\title{
Bullying victimisation and risk of self harm in early adolescence: longitudinal cohort study
}

\author{
(@) (®) OPEN ACCESS
}

\author{
Helen L Fisher MRC population health scientist ${ }^{1}$, Terrie E Moffitt professor of social behaviour and \\ development ${ }^{123}$, Renate M Houts senior research statistician ${ }^{23}$, Daniel W Belsky postdoctoral \\ fellow ${ }^{34}$, Louise Arseneault reader in developmental psychology ${ }^{1}$, Avshalom Caspi professor of \\ personality development ${ }^{123}$
}

${ }^{1}$ MRC Social, Genetic and Developmental Psychiatry Centre, Institute of Psychiatry, King's College London, London SE5 8AF, UK; ${ }^{2}$ Institute for Genome Sciences and Policy, Duke University, Durham, NC, USA; ${ }^{3}$ Departments of Psychology \& Neuroscience and Psychiatry \& Behavioral Sciences, Duke University; ${ }^{4}$ Department of Health Policy and Management, Gillings School of Public Health, University of North Carolina at Chapel Hill, NC, USA

\begin{abstract}
Objectives To test whether frequent bullying victimisation in childhood increases the likelihood of self harming in early adolescence, and to identify which bullied children are at highest risk of self harm.

Design The Environmental Risk (E-Risk) longitudinal study of a nationally representative UK cohort of 1116 twin pairs born in 1994-95 (2232 children).

Setting England and Wales, United Kingdom.

Participants Children assessed at 5, 7, 10, and 12 years of age.

Main outcome measures Relative risks of children's self harming behaviour in the six months before their 12th birthday.

Results Self harm data were available for 2141 children. Among children aged 12 who had self harmed $(2.9 \% ; n=62)$, more than half were victims of frequent bullying (56\%; $n=35)$. Exposure to frequent bullying predicted higher rates of self harm even after children's pre-morbid emotional and behavioural problems, low IQ, and family environmental risks were taken into account (bullying victimisation reported by mother: adjusted relative risk $1.92,95 \%$ confidence interval 1.18 to 3.12 ; bullying victimisation reported by child: $2.44,1.36$ to 4.40 ). Victimised twins were more likely to self harm than were their non-victimised twin sibling (bullying victimisation reported by mother: $13 / 162 v 3 / 162$, ratio $=4.3,95 \%$ confidence interval 1.3 to 14.0 ; bullying victimisation reported by child: $12 / 144 v 7 / 144$, ratio $=1.7,0.71$ to 4.1 ). Compared with bullied children who did not self harm, bullied children who self harmed were distinguished by a family history of attempted/completed suicide, concurrent mental health problems, and a history of physical maltreatment by an adult.
\end{abstract}

Conclusions Prevention of non-suicidal self injury in young adolescents should focus on helping bullied children to cope more appropriately with their distress. Programmes should target children who have additional mental health problems, have a family history of attempted/completed suicide, or have been maltreated by an adult.

\section{Introduction}

Bullying by peers is a major problem; approximately $25 \%$ of children in the United Kingdom report exposure to such victimisation. ${ }^{1}$ Bullying victimisation is associated with a myriad of emotional and behavioural problems throughout adolescence. ${ }^{2}$ Over the past few years, the media have focused public attention on instances of suicide and self harm among adolescents who have been bullied, and a commensurate rise in anti-bullying policies and laws has occurred on both sides of the Atlantic. ${ }^{34}$ Surprisingly, very few studies have tested the assumption that exposure to bullying in childhood increases the likelihood that a child or adolescent will self harm. Existing studies are often limited by cross sectional designs, the possibility that unmeasured background risk factors can lead children both to be victimised and to self harm (selection effects), and reliance on the same person to report both exposure to bullying and self harm behaviour, which may create spurious associations (reporter bias). ${ }^{5-8}$ Moreover, a need exists for research into self harm as early as possible in adolescence, to inform prevention of injuries.

Randomised trials exposing children to bullying are clearly unethical. Instead, we added several design features to an observational study to strengthen inferences that could be drawn 
about the effects of bullying victimisation on self harm. Firstly, we used a prospective longitudinal study following a nationally representative cohort of children from early childhood to 12 years of age, which enabled us to control statistically for a range of potentially confounding and pre-morbid selection effects. Secondly, because our cohort comprises twins, we were able to carry out a co-twin-control analysis among pairs discordant for bullying victimisation, to test if the bullied sibling was more likely to self harm than the non-bullied sibling, despite their shared family background. Thirdly, to minimise reporter bias and ascertain the robustness of our findings across different reporters, we measured children's exposure to bullying by interviewing both the children and their mothers. Thus, because mothers might not be aware of all of their children's exposure to bullying, we tested the association between the 12 year old children's own reports of bullying victimisation and their self harm outcomes. However, because in theory children who self harm might give exaggerated reports of their exposure to bullying as a result of co-morbid psychological difficulties, we also tested the association between mothers' reports of bullying victimisation and children's self harm outcomes. Fourthly, our longitudinal design allowed us to establish temporal ordering by testing the association between mothers' prospective reports of bullying victimisation up to the age 10 assessment and children's self harm outcomes at the age 12 assessment.

Even if bullying victimisation is linked to increased risk of self harm, most bullied children do not resort to self harm. Given the ubiquity of bullying, doctors, social care professionals, teachers, and parents need help to identify which bullied children are at greatest risk, to target interventions effectively. Several factors are known to increase the risk of self harm: being brought up in a deprived area, a family history of self harming behaviour, maltreatment, co-occurring behavioural and emotional problems, and a low IQ have all been associated with high rates of self harm. ${ }^{9}{ }^{10}$ To inform clinical practice, we examined which of these family level and child level characteristics could help to identify, among bullied children, who is at greatest risk of self harm.

\section{Method \\ Study cohort}

Participants were members of the Environmental Risk (E-Risk) study, which tracks the development of a birth cohort of 2232 British children. The sample was drawn from a larger birth register of twins born in England and Wales in 1994-95. ${ }^{11}$ Full details about the sample are reported elsewhere. ${ }^{12}$ Briefly, the E-Risk sample was constructed in 1999-2000, when 1116 (93\% of those eligible) families with same sex 5 year old twins participated in home visit assessments. Families were recruited to represent the UK population of families with newborns in the 1990s, on the basis of residential location throughout England and Wales and mother's age (older mothers having twins via assisted reproduction were under-selected, and teenage mothers with twins were over-selected). We used this sampling to replace high risk families who were selectively lost to the register through non-response and to ensure sufficient numbers of children growing up in high risk environments. The sample includes 55\% monozygotic and 45\% dizygotic twin pairs. Sex is evenly distributed within zygosity (49\% male). Follow-up home visits took place when the children were aged 7 (98\% participation), 10 (96\% participation), and, most recently, 12 years (96\% participation).

\section{Bullying victimisation}

Bullying victimisation was assessed during interviews with mothers when the children were aged 7 and 10 years, and separately in private interviews with the children during home visits when the children were 12 years old. Details of psychometric measurements for the bullying measures reported here have been described previously. ${ }^{13}{ }^{14}$ We explained to the mother or child that: "someone is being bullied when another child says mean and hurtful things, makes fun, or calls a person mean and hurtful names; completely ignores or excludes someone from their group of friends or leaves them out of things on purpose; hits, kicks, or shoves a person, or locks them in a room; tells lies or spreads rumours about them; or does other hurtful things like these. We call it bullying when these things happen often and it is difficult for the person being bullied to stop it happening. We do not call it bullying when it is done in a friendly or playful way." When bullying was reported, the interviewer asked the mother or child to describe what happened. An independent rater later checked notes taken by the interviewers to verify that the events described related to instances of bullying, operationally defined as evidence of repeated harmful actions between children where a power differential existed between the bully and the victim. This review was done blind to data on self harm. Mothers' and children's narratives of bullying experiences were coded as "never," "yes, but isolated incidents," or "frequently." Children were also asked directly if they had been bullied "a lot." Of the cohort children, $16.5 \%$ (350/2127) were reported by their mothers to have been frequently bullied before age 10 , and $11.2 \%$ (237/2124) of the children reported themselves to have been bullied a lot before age 12 .

\section{Self harm}

Mothers were asked whether each twin had ever deliberately harmed him/herself or attempted suicide in the previous six months, as part of a face to face interview when the children were aged 12 . Mothers who responded positively to this question were asked to provide a description of what took place. An independent rater blind to other data later checked the notes taken during the interview to verify that the description provided was clearly an act of self harm. We asked only mothers, and not children, to report the child's self harm because of ethical considerations. Examples of self harming behaviours included cutting and biting arms, pulling out clumps of hair, banging head against walls, and attempted suicides by strangulation. Of the cohort, $2.9 \%(62 / 2141)$ had self harmed; of these children, $52 \%(\mathrm{n}=32)$ were girls.

\section{Potential confounding variables}

Mothers reported on their children's exposure to maltreatment during a standardised clinical interview protocol, ${ }^{15}{ }^{16}$ used when the child was aged 5, 7, 10, and 12 years. Only those children whom the interviewers rated as having definitely experienced physical or sexual harm by an adult before age 12 were considered to have been maltreated. ${ }^{17} \mathrm{We}$ assessed internalising and externalising problems at age 5 by using the child behavior checklist in face to face interviews with mothers and the teacher's report form by mail for teachers. ${ }^{18}{ }^{19}$ The internalising problems scale is the sum of items in the withdrawn and anxious/depressed subscales, and the externalising problems scale is the sum of items from the aggressive and delinquent behaviour subscales. We summed and standardised mothers' and teachers' reports to create cross-informant scales. We tested children's IQ at age 5 individually by using a short form of the 
Wechsler preschool and primary scale of intelligence-revised. ${ }^{20} 21$

Supplementary table A shows that associations between the potential confounding variables (maltreatment, internalising and externalising problems, IQ) and exposure to bullying victimisation and self harm were all statistically significant.

\section{Indicators of clinical concern}

We constructed socioeconomic deprivation at age 5 from a standardised composite of household income, parents' highest education, and parents' highest occupational grade. ${ }^{22}$ We defined deprivation as the lowest third of the distribution. We determined attempted or completed suicide by any of the child's biological mother, father, grandparents, aunts, or uncles from reports by biological parents, according to a standardised and validated protocol. ${ }^{23}$ We calculated a modified Reed's score, which takes into account the number of affected relatives given the size and demographic structure of the family, ${ }^{24}$ and we considered children whose score was at or above the 80th centile to have a strong positive family history of suicide. When the children were aged 10 and 12 , we interviewed mothers about the presence of attention/hyperactivity and conduct problems by using items drawn from the Diagnostic and Statistical Manual of Mental Disorders, fourth edition (DSM-IV). ${ }^{25}$ We considered attention-deficit/hyperactivity disorder to be present if the child met DSM-IV criteria for this disorder at either 10 or 12 years of age; similarly, we deemed children to have conduct disorder if they met the relevant DSM-IV criteria at either of these ages. We classified children as having extreme borderline personality characteristics if they scored at or above the 95th centile on a shortened version of the Shedler-Westen assessment procedure-200 for adolescents (SWAP-200A), ${ }^{26}$ which mothers completed when the twins were aged $12 .{ }^{27}$ We calculated the score with the self harm item excluded. At age 12, children completed the 10 item version of the multidimensional anxiety scale for children (MASC) ${ }^{28}$ Children scoring at or above the 95th centile (raw score of 13 or more) constituted the "extreme" anxiety group. We used scores of 20 or more on the children's depression inventory (CDI) to indicate clinically significant depressive symptoms. ${ }^{29}{ }^{30} \mathrm{We}$ assessed the definite presence of any psychotic symptoms during a private interview conducted with each child, as previously reported. ${ }^{31}$ Finally, we individually tested children's IQ at age 12 by using a short form of the Wechsler intelligence scale for children, fourth edition. ${ }^{32} 33$

\section{Statistical analysis}

Firstly, we tested the relation between mothers' and children's reports of frequent bullying and mothers' reports of their self harm by using modified Poisson regression to estimate relative risks and robust $95 \%$ confidence intervals, ${ }^{34}$ both unadjusted and then adjusted for the potentially confounding effects of physical maltreatment by adults, internalising and externalising problems at age 5, and IQ at age 5. We also calculated relative risks separately for girls and boys and evaluated the equality of the bullying coefficients across the sexes with an approach called "seemingly unrelated regression" using the "suest" command in Stata (v11.2). Secondly, we did a discordant twin analysis to rule out family-wide influences on the association between bullying victimisation and self harm. ${ }^{35}$ Here, we tested the hypothesis that bullied twins would be more likely to self harm than their non-bullied co-twins over and above shared familial environmental risks. Thirdly, we did a series of logistic regressions to test which risk factors could help to identify which bullied children would engage in self harm. We evaluated the following risks: family adversities (socioeconomic deprivation, family history of attempted/completed suicide, physical maltreatment), children's concurrent mental health problems, and children's low IQ. Finally, we used the "punaf" command in Stata (v11.2) to calculate the population attributable fraction for self harm based on exposure to bullying victimisation (reported by either mother or child) in this sample. We corrected all analyses (except the twin discordance analysis) for the non-independence of the twin observations by using the Huber-White variance estimator. We did a sensitivity analysis using multi-level mixed models in SAS with the PROC GLIMMIX procedure and obtained almost identical results (data not shown).

\section{Results \\ Does frequent bullying predict self harm?}

Exposure to frequent bullying by peers before age 12 was associated with an increased risk of self harm at 12 years of age, whether bullying was reported by mothers (relative risk 3.53 , 95\% confidence interval 2.10 to 5.93 ) or by children themselves (3.33, 1.91 to 5.82). This association was equally evident among both boys and girls, for both reporting sources (figure $\Downarrow$ ).

Therefore, the remaining analysis included both sexes together.

\section{Can maltreatment explain association between bullying and self harm?}

Bullying and parental maltreatment often occur to the same children, ${ }^{36}$ and problem parenting has been implicated in elevated rates of self harm. ${ }^{9}$ Therefore, we tested whether exposure to physical maltreatment could account for the association between bullying and self harm. However, the association between frequent bullying and self harm behaviour remained after we controlled for lifetime exposure to physical maltreatment (table $1 \Downarrow)$.

\section{Can early mental health problems explain association between bullying and self harm?}

Children's emotional or behavioural problems may make them greater targets for bullying and also increase the likelihood that they will engage in self harm. ${ }^{2}$ Nonetheless, the greater risk of self harm after exposure to bullying remained when we took these pre-morbid problems into account (table $1 \Downarrow$ ).

\section{Can low IQ explain association between bullying and self harm?}

Children with low cognitive abilities are at greater risk of being targeted by bullies, ${ }^{37}$ as well as engaging in self harm behaviours. ${ }^{9}$ However, adjustment for IQ at age 5 did not substantially alter the association between bullying and self harm (table $1 \Downarrow$ ).

\section{Can family environment explain association between bullying and self harm?}

Another possibility is that factors within the family environment (such as poverty, parental psychopathology, domestic violence) could account for the association we observed between bullying and self harm. To rule out the influence of these shared environmental risk factors, we compared twins within the same family to determine whether bullied twins were more likely to self harm than their non-bullied age and sex matched co-twin. Using mothers' reports, 162 twin pairs were discordant for bullying, and the bullied twins were significantly more likely to self harm than were their non-bullied co-twins $(13(8.0 \%) v$ $3(1.9 \%)$; ratio $=4.3,95 \%$ confidence interval 1.3 to 14.0$)$. 
Turning to children's self reports, 144 were discordant for bullying, and here we saw a similar trend for the bullied twins to self harm compared with their co-twins $(12$ (8.3\%) v 7 (4.9\%); ratio $=1.7,0.71$ to 4.1 )

\section{Can bullied children who will engage in self harm be identified?}

Most children exposed to bullying (more than 90\%) did not engage in self harm. Therefore, we tested which factors discriminated between bullied children who self harmed and bullied children who did not (table $2 \Downarrow$ ). For both mothers' and children's reports, bullied children who engaged in self harming behaviours were significantly more likely to have a family member who had attempted/completed suicide and to have been physically maltreated by an adult. They were also more likely to present with conduct disorder, borderline personality characteristics, depression, and psychotic symptoms than were bullied children who did not self harm.

\section{How much self harm might be attributed to bullying?}

Among the 62 children who self harmed at age 12, 35 (56\%) had been victimised by bullying, according to either the mother or child informant. This yields a population attributable fraction suggesting that if bullying could have been eradicated (and everything else remained the same), a sizeable proportion of the cases of self harm could potentially have been prevented (42.8\%, $95 \%$ confidence interval $23.1 \%$ to $57.5 \%)$.

\section{Discussion}

Frequent exposure to bullying by peers during childhood increased the risk of deliberate self harm among young adolescents aged 12 years. We documented that this association was present at the beginning of adolescence, was similar for reports of bullying by mothers and accounts of bullying by children, and was independent of potential confounding selection effects of maltreatment by an adult, family environmental risk factors, early behavioural and emotional problems, and low IQ. We also showed that bullied children who self harmed differed from their bullied counterparts who did not self harm in having a family history of suicidal behaviour, being physically maltreated by an adult, and having co-occurring mental health problems (conduct disorder, borderline personality characteristics, depressive or psychotic symptoms).

\section{Possible explanations for findings}

Frequent exposure to bullying is independently associated with high levels of distress. ${ }^{2}$ But why do a small proportion of bullied children choose to use self harm rather than other coping strategies (such as exercise or talking) to deal with these emotions? One possibility is that 12 year old children lack opportunities for reducing distress that are available to adults, such as self medication with alcohol or cigarettes, working out at the gym, or excessive food consumption. Children may use self harm after their attempts to talk to others about their distress have not been successful and more drastic attention seeking behaviours are thus needed. The last explanation is probably more likely in abusive or neglectful family environments where the child's voice is seldom heard owing to their own fear of being "punished" if they speak out or to the unavailability of empathetic caregivers. ${ }^{38} 39$ This hypothesis is partially supported by the greater prevalence of self harm among bullied children in our sample who were also physically maltreated. Repeated exposure to such victimisation by adults as well as bullying by peers may also result in the child developing a critical view of $\mathrm{him} / \mathrm{herself}$ and using self harm as a means of self punishment. $^{4041}$

Witnessing or hearing about others engaging in self harm is also likely to increase the probability that children will use this behaviour. ${ }^{42} \mathrm{We}$ found that bullied children who had a family member who had attempted or completed suicide were more likely to self harm, suggesting that such self destructive coping strategies may be learnt from close others. Familial transmission via impulsive aggression is also likely among these children. ${ }^{43}$ As self harm can be used to help to regulate emotions, ${ }^{44}$ children who experience emotions very intensely or are affectively dysregulated may be more likely to use this coping strategy after bullying victimisation. This hypothesis is borne out in our sample, where we found that bullied children with concurrent psychological difficulties, many of which involve extreme emotions or difficulties in regulation of affect, ${ }^{45-48}$ were at greater risk of self harm.

\section{Potential implications}

Bullying victimisation seemed to be a major antecedent of self harm in our cohort of 12 year olds; more than half of self harmers had been bullied frequently. Although more effective programmes to prevent bullying occurring in schools are needed, ${ }^{49}$ our findings suggest that efforts should also focus on improving the ways in which children cope with emotional distress arising from bullying victimisation. Although only a small proportion of bullied children in this sample engaged in self harm, this is clearly too many and victims need to be provided with alternative coping strategies from a young age. The effectiveness of such interventions would also need to be investigated. Furthermore, our results suggest that, when tested, these interventions should be aimed initially at bullied children who also have additional indicators of concern (a family member who has attempted/completed suicide, history of physical abuse, or concurrent mental health problems), as these children need the most immediate intervention. This will require schools and health professionals who come into contact with bullied children to assess these indicators of concern and also to ascertain whether the help a child has is sufficient.

This study adds to the growing literature showing that bullying during the early years of school can have extremely detrimental consequences for some children by the time they reach adolescence. ${ }^{50-53}$ This finding is even more concerning given that studies have suggested that early patterns of self harm can persist through adolescence into adulthood and increase the risk of later psychological problems. ${ }^{104-56}$ Therefore, such maladaptive coping strategies need to be tackled in childhood and early adolescence before they become a persistent problem or lead to serious injury or death.

\section{Limitations of study}

Our sample included rather a small number of children who had engaged in self harm, and this may have led to unstable or biased estimates of the size of the associations between bullying victimisation and self harm, particularly when controlling for confounders. Therefore our results need to be replicated in samples with a higher prevalence of such behaviours. Nevertheless, this study provides first evidence of an increased risk of self harming behaviours at the beginning of adolescence among bullied children from a population representative birth cohort unbiased by referral for treatment. The sample comprised twins, so the results may not generalise to singletons. However, the prevalence of bullying victimisation and mental health 
problems has been shown to be the same for twins and singletons. ${ }^{137}$ Moreover, using the twin design we were able to show that the association between bullying and self harm was maintained when environmental risks within the family were taken into account. Although we examined both mothers' and children's reports of bullying, we had access only to mothers' reports about the children's self harm, which may have resulted in under-detection of this behaviour. Similarly, only mothers reported on children's exposure to maltreatment, which may also have led to under-reporting of this confounding variable. ${ }^{58}$ As the cohort grows older, we will be able to interview the children about self harm and past exposure to maltreatment.

\section{Conclusions}

Bullying by peers is a major problem during the early school years. ${ }^{1}$ This study found that before 12 years of age a small proportion of children frequently exposed to this form of victimisation already deliberately harmed themselves and in some cases attempted to take their own lives. Frequent victimisation by peers increased the risk of self harm independently of a range of potential confounders. Children exposed to family adversity or who had specific concurrent mental health difficulties had the greatest risk of engaging in self destructive behaviours after exposure to bullying by peers. Therefore, schools and healthcare professionals aiming to prevent adolescents' self harm should reduce bullying and introduce self harm risk reduction programmes for bullied children with any of the following risk factors: a family history of suicidal behaviour, maltreatment at home, symptoms of depression or psychosis, conduct problems, or borderline personality characteristics.

We acknowledge the study families and the twins' teachers for their help and participation. We also thank Michael Rutter and Robert Plomin of the Institute of Psychiatry, King's College London, UK, and members of the E-Risk team for their dedication, hard work, and insights.

Contributors: HLF was involved in reviewing the literature and in analysing and interpreting data and wrote the draft manuscript. All other authors reviewed the report. TEM was involved in the conception, design, and management of the study and in analysing and interpreting data. DWB contributed to study design and statistical analysis. RMH contributed to statistical analysis. LA was involved in the conception, design, and management of the study. AC was involved in the conception, design, and management of the study and in analysing and interpreting data. HLF is the guarantor.

Funding: The E-Risk Study is funded by the Medical Research Council (MRC; G9806489 and G1002190). Additional support was provided by the Economic and Social Research Council (RES-177-25-0013), the US National Institute of Child Health and Human Development (HD061298), the US National Institute of Mental Health (MH077874), the British Academy, the Nuffield Foundation, and the Jacobs Foundation. HLF is funded by an MRC population health scientist fellowship (G1002366). The sponsors played no part in the design or conduct of the study, the analysis or interpretation of data, or the writing of the article and the decision to submit it for publication.

Competing interests: All authors have completed the Unified Competing Interest form at http://www.icmje.org/coi_disclosure.pdf (available on request from the corresponding author) and declare: no support from any organisation for the submitted work; no financial relationships with any organisations that might have an interest in the submitted work in the previous three years; and no other relationships or activities that could appear to have influenced the submitted work.
Ethical approval: This study was approved by the UK Multicentre Research Ethics Committee (08/H0305/49). The Joint South London and Maudsley and the Institute of Psychiatry Ethics Committee (UK) approved each phase of the study.

Data sharing: The statistical code and dataset are available from principal investigator Louise Arseneault at louise.arseneault@kcl.ac.uk.

Radford L, Corral S, Bradley C, Fisher H, Bassett C, Howat N, et al. Child abuse and neglect in the UK today. National Society for the Prevention of Cruelty to Children, 2011.

2 Arseneault L, Bowes L, Shakoor S. Bullying victimization in youths and mental health problems: "much ado about nothing"? Psychol Med 2010;40:717-29.

3 Department for Children, Schools and Families. Safe from bullying: guidance for local authorities and other strategic leaders on reducing bullying in the community. Department for Children, Schools and Families, 2009.

4 Hu W. Bullying law puts New Jersey schools on spot. New York Times 2011 Aug 30.

5 Garisch JA, Wilson MS. Vulnerabilities to deliberate self-harm among adolescents: the role of alexithymia and victimization. Br J Clin Psychol 2010;49:151-62.

6 Jutengren G, Kerr M, Stattin H. Adolescents' deliberate self-harm, interpersonal stress, and the moderating effects of self-regulation: a two-wave longitudinal analysis. J Sch Psychol 2011:49:249-64.

7 Landstedt E, Gådin KG. Deliberate self-harm and associated factors in 17-year-old Swedish students. Scand J Public Health 2011;39:17-25.

8 McMahon EM, Reulbach U, Keeley H, Perry IJ, Arensman E. Bullying victimization, self harm and associated factors in Irish adolescent boys. Soc Sci Med 2010;71:1300-7.

9 Hawton K, James A. Suicide and deliberate self-harm in young people. BMJ 2005;330:891-4.

10 Skegg K. Self-harm. Lancet 2005;366:1471-83.

11 Trouton A, Spinath FM, Plomin R. Twins early development study (TEDS): a multivariate, longitudinal genetic investigation of language, cognition and behavior problems in childhood. Twin Res 2002;5:444-8.

12 Moffitt TE. Teen-aged mothers in contemporary Britain. J Child Psychol Psychiatry 2002;43:727-42.

13 Arseneault L, Walsh E, Trzesniewski K, Newcombe R, Caspi A, Moffitt TE. Bullying victimization uniquely contributes to adjustment problems in young children: a nationally representative cohort study. Pediatrics 2006;118:130-8.

14 Shakoor S, Jaffee SR, Andreou P, Bowes L, Ambler AP, Caspi A, et al. Mothers and children as informants of bullying victimization: results from an epidemiological cohort of children. J Abnorm Child Psychol 2011;39:379-87.

15 Dodge KA, Bates JE, Pettit GS. Mechanisms in the cycle of violence. Science 1990;250:1678-83.

16 Lansford JE, Dodge KA, Pettit GS, Bates JE, Crozier J, Kaplow J. Long-term effects of early child physical maltreatment on psychological, behavioral, and academic problems in adolescence: a 12-year prospective study. Arch Pediatr Adolesc Med 2002;156:824-30.

17 Jaffee S, Caspi A, Moffitt TE, Polo-Tomas M, Taylor A. Individual, family, and neighborhood factors predict children's resilience to maltreatment: a cumulative stressors model. Child Abuse Negl 2007;31:231-53.

18 Achenbach TM. Manual for the Child Behavior Checklist and 1991 profile. University of Vermont, 1991.

19 Achenbach TM. Manual for the Teacher's Report Form and 1991 profile. University of Vermont, 1991.

20 Sattler JM. Assessment of children: WISC-III and WPPSI-R supplement. JM Sattler, 1992.

21 Wechsler D. Wechsler Preschool and Primary Scale of Intelligence-Revised. Psychological Corporation, 1991

22 Melchior M, Caspi A, Howard LM, Ambler AP, Bolton H, Mountain N, et al. Mental health context of food insecurity: a representative cohort of families with young children. Pediatrics 2009;124:e564-72.

23 Milne BJ, Caspi A, Crump R, Poulton R, Rutter M, Sears MR, et al. The validity of the family history screen for assessing family history of mental disorders. Am J Med Genet B Neuropsychiatr Genet 2009;150B:41-9.

24 Milne BJ, Moffitt TE, Crump R, Poulton R, Rutter M, Sears MR, et al. How should we construct psychiatric family history scores? A comparison of alternative approaches from the Dunedin Family Health History Study. Psychol Med 2008;38:1793-802.

25 American Psychiatric Association. Diagnostic and statistical manual of mental disorders, 4th edition. American Psychiatric Association, 1994.

26 Westen D, Shedler J, Durrett C, Glass S, Martens A. Personality diagnoses in adolescence: DSM-IV axis II diagnoses and an empirically derived alternative. Am J Psychiatry 2003;160:952-66.

27 Belsky DW, Caspi A, Arseneault L, Bleidorn W, Fonagy P, Goodman M, et al. Etiological features of borderline personality-related characteristics in a birth cohort of 12 year-old children. Dev Psychopathol 2012;24:251-65.

28 March JS. Manual for the Multidimensional Anxiety Scale for Children (MASC). Multi-Health Systems, 1997.

29 Rivera CL, Bernal G, Rossello G. The Children's Depression Inventory (CDI) and the Beck Depression Inventory (BDI): their validity as screening measures for major depression in a group of Puerto Rican adolescents. Int J Clin Health Psychol 2005;5:485-98.

30 Kovacs M. Children's Depression Inventory (CDI) manual. Multi-Health Systems, 1992.

31 Polanczyk G, Moffitt TE, Arseneault L, Cannon M, Ambler A, Keefe RSE, et al. Childhood psychotic symptoms share etiological and clinical features with adult schizophrenia: results from a representative birth cohort. Arch Gen Psychiatry 2010;67:328-38.

32 Sattler JM, Dumont R. Assessment of children: WISC-IV and WPPSI-III supplement. JM Sattler, 2004.

33 Wechsler D. Wechsler Intelligence Scale for Children. 4th ed. UK version. Harcourt Assessment, 2003.

34 Zou G. A modified poisson regression approach to prospective studies with binary variables. Am J Epidemiol 2004;159:702-6.

35 McGue M, Osler M, Christensen K. Causal inference and observational research: the utility of twins. Perspect Psychol Sci 2010;5:546-56.

36 Bowes L, Arseneault L, Maughan B, Taylor A, Caspi A, Moffitt TE. School, neighborhood, and family factors are associated with children's bullying involvement: a nationally representative longitudinal study. J Am Acad Child Adolesc Psychiatry 2009;48:545-53. 


\section{What is already known on this topic}

Bullying victimisation by peers is a prevalent problem in the United Kingdom

Cross sectional studies suggest that exposure to bullying may be associated with increased rates of self harm

Short term follow-up studies have indicated that such victimisation could be a risk for self harming behaviours in mid to late adolescence

\section{What this study adds}

Frequent exposure to bullying during childhood increases victims' risk of self harm; as many as half of 12 year olds who self harmed were victims of frequent bullying

Self harm was not explained by pre-morbid risk factors that may lead to both victimisation and self-harm

Bullied children who self-harmed were more likely to have been maltreated, to have a family history of attempted/completed suicide, and to experience concurrent mental health problems

37 Martlew M, Hodson J. Children with mild learning difficulties in an integrated and in a special school: comparisons of behaviour, teasing and teachers' attitudes. $\mathrm{Br} J$ Educ Psychol 1991:61:355-72.

38 Herba CM, Ferdinand RF, Stijnen T, Veenstra R, Oldehinkel AJ, Omel J, et al. Victimization and suicide ideation in the TRAILS study: specific vulnerabilities of victims. $J$ Child Psychol Psychiatry 2008:49:867-76.

39 Wedig MM, Nock MK. Parental expressed emotion and adolescent self-injury. J Am Acad Child Adolesc Psychiatry 2007:46:1171-8.

40 Glassman LH, Weierich MR, Hooley JM, Deliberto TL, Nock MK. Child maltreatment, nonsuicidal self-injury, and the mediating role of self-criticism. Behav Res Ther 2007;45:2483-90

41 Nock MK, Prinstein MJ. A functional approach to the assessment of self-mutilative behavior. $J$ Consult Clin Psychol 2004;72:885-90.

42 McMahon EM, Reulbach U, Corcoran P, Keeley HS, Perry IJ, Arensman E. Factors associated with deliberate self-harm among Irish adolescents. Psychol Med 2010;40:1811-9.

43 Brent DA, Mann JJ. Familial pathways to suicidal behavior-understanding and preventing suicide among adolescents. N Engl J Med 2006;355:2719-21.

44 Nock MK. Why do people hurt themselves? New insights into the nature and function of self-injury. Curr Dir Psychol Sci 2009;18:78-83.

45 Cappadocia MC, Desrocher M, Pepler D, Schroeder JH. Contextualizing the neurobiology of conduct disorder in an emotion dysregulation framework. Clin Psychol Rev 2009;29:506-18.

46 Gotlib IH, Joormann J. Cognition and depression: current status and future directions Annu Rev Clin Psychol 2010;6:285-312.

47 Myin-Germeys I, van Os J. Stress-reactivity in psychosis: evidence for an affective pathway to psychosis. Clin Psychol Rev 2007:27:409-24.

48 Skodol AE, Gunderson JG, Pfohl B, Widiger TA, Livesley WJ, Siever LJ. The borderline diagnosis I: psychopathology comorbidity, and personality structure. Biol Psychiatry 2002;51:936-50.

49 Smith PK, Ananiadou K, Cowie H. Interventions to reduce school bullying. Can J Psychiatry 2003:48:591-9.
50 Arseneault L, Milne BJ, Taylor A, Adams F, Delgado K, Caspi A, et al. Being bullied as an environmentally mediated contributing factor to children's internalizing problems. Arch Pediatr Adolesc Med 2008:162:145-50.

51 Kim YS, Leventhal BL, Koh YJ, Hubbard A, Boyce WT. School bullying and youth violence: causes or consequences of psychopathologic behavior? Arch Gen Psychiatry 2006;63:1035-41.

52 Nansel TR, Overpeck MD, Haynie DL, Ruan WJ, Scheidt PC. Relationships between bullying and violence among US youth. Arch Pediatr Adolesc Med 2003;157:348-53.

53 Schreier A, Wolke D, Thomas K, Horwood J, Hollis C, Gunnell D, et al. Prospective study of peer victimization in childhood and psychotic symptoms in a nonclinical population at age 12 years. Arch Gen Psychiatry 2009;66:527-36.

54 Fergusson DM, Horwood LJ, Ridder EM, Beautrais AL. Suicidal behaviour in adolescence and subsequent mental health outcomes in young adulthood. Psychol Med 2005;35:983-93.

55 Harrington R, Pickles A, Aglan A, Harrington V, Burroughs H, Kerfoot M. Early adult outcomes of adolescents who deliberately poisoned themselves. J Am Acad Child Adolesc Psychiatry 2006;45:337-45

56 Steinhausen HC, Bösiger R, Metzke CW. Stability, correlates, and outcome of adolescent suicidal risk. J Child Psychol Psychiatry 2006;47:713-22.

57 Gjone H, Novik TS. Parental ratings of behavioural problems: a twin and general population comparison. J Child Psychol Psychiatry 1995;36:1213-24.

58 Fisher HL, Bunn A, Jacobs C, Moran P, Bifulco A. Concordance between mother and offspring retrospective reports of childhood adversity. Child Abuse Negl 2011;35:117-22.

\section{Accepted: 15 March 2012}

\section{Cite this as: BMJ 2012;344:e2683}

This is an open-access article distributed under the terms of the Creative Commons Attribution Non-commercial License, which permits use, distribution, and reproduction in any medium, provided the original work is properly cited, the use is non commercial and is otherwise in compliance with the license. See: http://creativecommons.org/licenses/by$\mathrm{nc} / 2.0 /$ and http://creativecommons.org/licenses/by-nc/2.0/legalcode. 


\section{Tables}

Table 1| Association of children's bullying victimisation (as assessed by mothers' reports and children's own reports) with self harm

\begin{tabular}{|c|c|c|c|c|c|}
\hline & \multicolumn{5}{|c|}{ Relative risk (95\% Cl) } \\
\hline & Model 1 & Model 2 & Model 3 & Model 4 & Model 5 \\
\hline \multicolumn{6}{|c|}{ Associations between bullying victimisation (mothers' reports) and self harm } \\
\hline Bullying victimisation & $3.53(2.10$ to 5.93$)$ & $2.54(1.55$ to 4.16$)$ & $2.43(1.49$ to 3.97$)$ & $3.29(1.95$ to 5.56$)$ & 1.92 (1.18 to 3.12$)$ \\
\hline $\begin{array}{l}\text { Maltreatment by adult before age } \\
12\end{array}$ & - & 4.94 (2.96 to 8.25$)$ & - & - & $3.02(1.75$ to 5.21$)$ \\
\hline Emotional problems at age 5 & - & - & $1.04(1.02$ to 1.06$)$ & - & 1.04 (1.01 to 1.06$)$ \\
\hline Behavioural problems at age 5 & - & - & $1.03(1.02$ to 1.04$)$ & - & 1.03 (1.02 to 1.04$)$ \\
\hline IQ at age 5 & - & - & - & $0.98(0.96$ to 1.00$)$ & 1.00 (0.98 to 1.01$)$ \\
\hline \multicolumn{6}{|c|}{ Associations between bullying victimisation (children's reports) and self harm } \\
\hline Bullying victimisation & 3.33 (1.91 to 5.82$)$ & 2.71 (1.52 to 4.84$)$ & 2.76 (1.60 to 4.78$)$ & $3.02(1.67$ to 5.47$)$ & 2.44 (1.36 to 4.40$)$ \\
\hline $\begin{array}{l}\text { Maltreatment by adult before age } \\
12\end{array}$ & - & $5.42(3.02$ to 9.73$)$ & - & - & 2.99 (1.69 to 5.31$)$ \\
\hline Emotional problems at age 5 & - & - & $1.04(1.02$ to 1.06$)$ & - & 1.04 (1.01 to 1.06 ) \\
\hline Behavioural problems at age 5 & - & - & 1.04 (1.02 to 1.05$)$ & - & $1.03(1.02$ to 1.04$)$ \\
\hline IQ at age 5 & - & - & - & $0.98(0.96$ to 1.00$)$ & 1.00 (0.98 to 1.02$)$ \\
\hline
\end{tabular}

Model $1=$ =unadjusted; model $2=$ adjusted for physical maltreatment by adults; model $3=$ adjusted for internalising and externalising problems at age 5 ; model $4=$ adjusted for IQ at age 5 ; model $5=$ adjusted for all confounders together. 
Table 2| Prevalence of indicators of clinical concern among frequently bullied children who did or did not self harm, for mothers' and children's reports of bullying. Values are numbers (percentages) unless stated otherwise

\begin{tabular}{|c|c|c|c|c|c|c|}
\hline \multirow[b]{2}{*}{ Risk factor } & \multicolumn{3}{|c|}{ Bullied children (mothers' report) } & \multicolumn{3}{|c|}{ Bullied children (children's report) } \\
\hline & $\begin{array}{l}\text { No self harm } \\
\quad(n=325)\end{array}$ & Self harm $(n=25)$ & Odds ratio $(95 \% \mathrm{Cl})$ & $\begin{array}{l}\text { No self harm } \\
(n=219)\end{array}$ & Self harm $(n=18)$ & Odds ratio $(95 \% \mathrm{Cl})$ \\
\hline \multicolumn{7}{|l|}{ Family adversities: } \\
\hline Socioeconomic deprivation & $139(43)$ & $18(72)$ & 3.44 (1.36 to 8.68$)$ & $95(43)$ & $11(61)$ & 2.05 (0.74 to 5.67$)$ \\
\hline $\begin{array}{l}\text { Family history of } \\
\text { attempted/completed suicide }\end{array}$ & $68 / 318(21)$ & $18 / 21(86)$ & 22.06 (6.15 to 79.10$)$ & $58 / 217(27)$ & $11 / 16(69)$ & 6.03 (1.94 to 18.73$)$ \\
\hline Maltreatment history & $39(12)$ & $15(60)$ & 11.00 (4.74 to 25.5$)$ & $21(10)$ & $6(33)$ & 4.71 (1.62 to 13.75$)$ \\
\hline \multicolumn{7}{|l|}{$\begin{array}{l}\text { Child's mental health } \\
\text { difficulties: }\end{array}$} \\
\hline ADHD diagnosis & 23/290 (8) & $7 / 18(39)$ & $7.39(2.91$ to 18.78$)$ & 20/188 (11) & $4 / 15(27)$ & 3.05 (0.88 to 10.55$)$ \\
\hline Conduct disorder diagnosis & 38/323 (12) & $12(48)$ & $6.92(2.79$ to 17.19$)$ & 19/212 (9) & $5 / 17(29)$ & 4.23 (1.28 to 14.02$)$ \\
\hline $\begin{array}{l}\text { Extreme borderline } \\
\text { characteristics }\end{array}$ & $32(10)$ & $16(64)$ & $16.28(6.45$ to 41.05$)$ & $27(12)$ & $10(56)$ & 8.89 (3.06 to 25.80$)$ \\
\hline Extreme anxiety symptoms & $18(6)$ & $3(12)$ & $2.32(0.69$ to 7.78$)$ & $40(18)$ & $5(28)$ & $1.72(0.56$ to 5.29$)$ \\
\hline $\begin{array}{l}\text { Clinically significant } \\
\text { depression }\end{array}$ & $16(5)$ & $7(28)$ & 7.5 (2.49 to 22.64$)$ & $28(13)$ & $6(33)$ & 3.39 (1.13 to 10.19$)$ \\
\hline Psychotic symptoms & $32(10)$ & $6(24)$ & 2.88 (1.12 to 7.44$)$ & $37(17)$ & $7(39)$ & 3.11 (1.09 to 8.85$)$ \\
\hline Mean (SD) child's IQ (12 years) & $98.4(15.7)$ & $92.1(14.4)$ & $0.97(0.95$ to 1.00$)$ & $96.7(15.8)$ & $98.6(14.9)$ & $1.01(0.98$ to 1.04$)$ \\
\hline
\end{tabular}

ADHD=attention-deficit/hyperactivity disorder. 


\section{Figure}
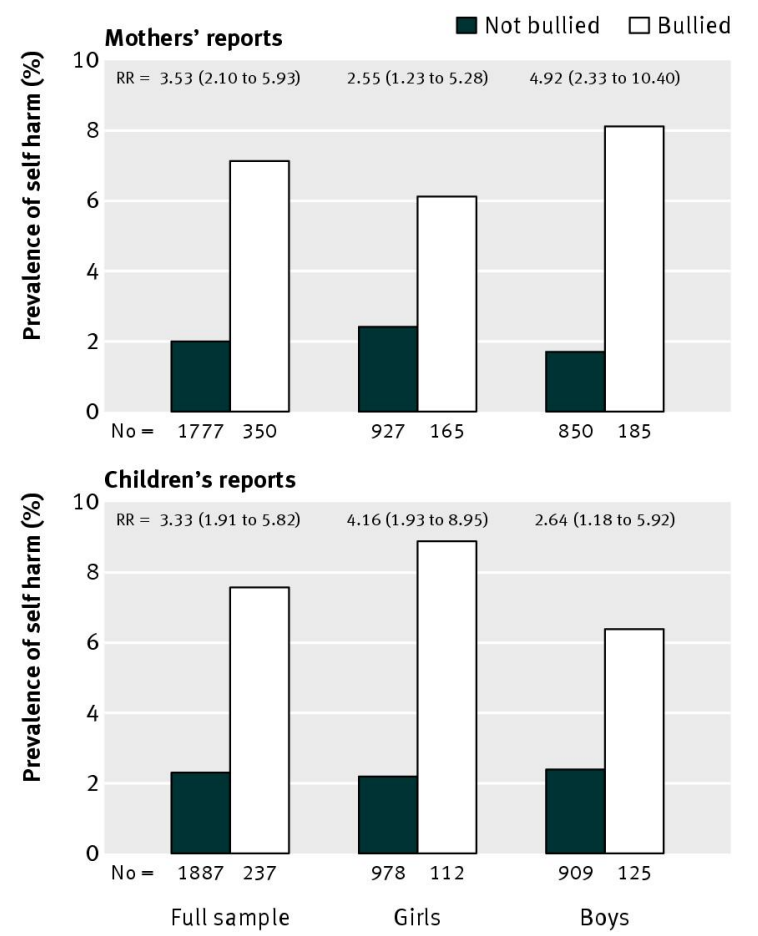

Prevalence of self harm at age 12 among frequently bullied and non-bullied children assessed by maternal reports of bullying (top panel) and children's own reports of bullying (bottom panel). Associations between bullying victimisation and self harm are expressed as relative risks (RR) with $95 \%$ confidence intervals 